\title{
Streamflow In The Sapucaí River Watershed, Brazil: Probabilistic Modeling, Reference Streamflow, And Regionalization
}

\author{
Marcel Abreu ${ }^{1}$, Micael Fraga ${ }^{2}$, Laura Almeida ${ }^{3}$, Felipe Silva ${ }^{4}$, Roberto Cecílio ${ }^{5}$, Gustavo \\ Lyra $^{1}$, and Rafael Delgado ${ }^{1}$ \\ ${ }^{1}$ Federal Rural University of Rio de Janeiro \\ ${ }^{2}$ Water Management Institute of Minas Gerais \\ ${ }^{3}$ Federal University of Viçosa Agricultural Science Centre \\ ${ }^{4}$ Universidade Vale do Rio Verde - Campus Tres Coracoes \\ ${ }^{5}$ Federal University of Espirito Santo
}

May 18, 2021

\begin{abstract}
This work aims to study the streamflow statistic patterns in the Sapucaí River watershed, state of Minas Gerais, Brazil. This study embraces the streamflow probabilistic modeling to determine the reference streamflow and, later, the streamflow regionalization to improve the water resources management. A 26-year-data series (1989 - 2014) of maximum, average, and minimum streamflow were used. Probability density functions were applied to the maximum and minimum daily streamflow to determine the recurrence periods. Long-term average annual and monthly streamflow were also calculated. Linear and nonlinear regressions were adjusted for the streamflow regionalization. The drainage area and the streamflow equivalent to the total rainfall (with and without abstractions) were used as predictor variables. The probability density functions that best adjusted the maximum streamflow data set were the Generalized Extreme Values, and for the minimum streamflow was the normal distribution. Linear and non-linear regressions were efficient $\left(\mathrm{R}^{2}>0.90\right.$ and $\mathrm{d}$ Willmott $\left.>0.97\right)$ in the regionalization process regardless of the predictor variables. However, a small statistical advantage was found for the adjustment of nonlinear regressions that used the predictor variables drainage area and the streamflow equivalent to the total rainfall (without abstractions).
\end{abstract}

\section{Hosted file}

Hydrological Processes Research Article.pdf available at https://authorea.com/users/284537/ articles/522438-streamflow-in-the-sapuca\%C3\%AD-river-watershed-brazil-probabilisticmodeling-reference-streamflow-and-regionalization 

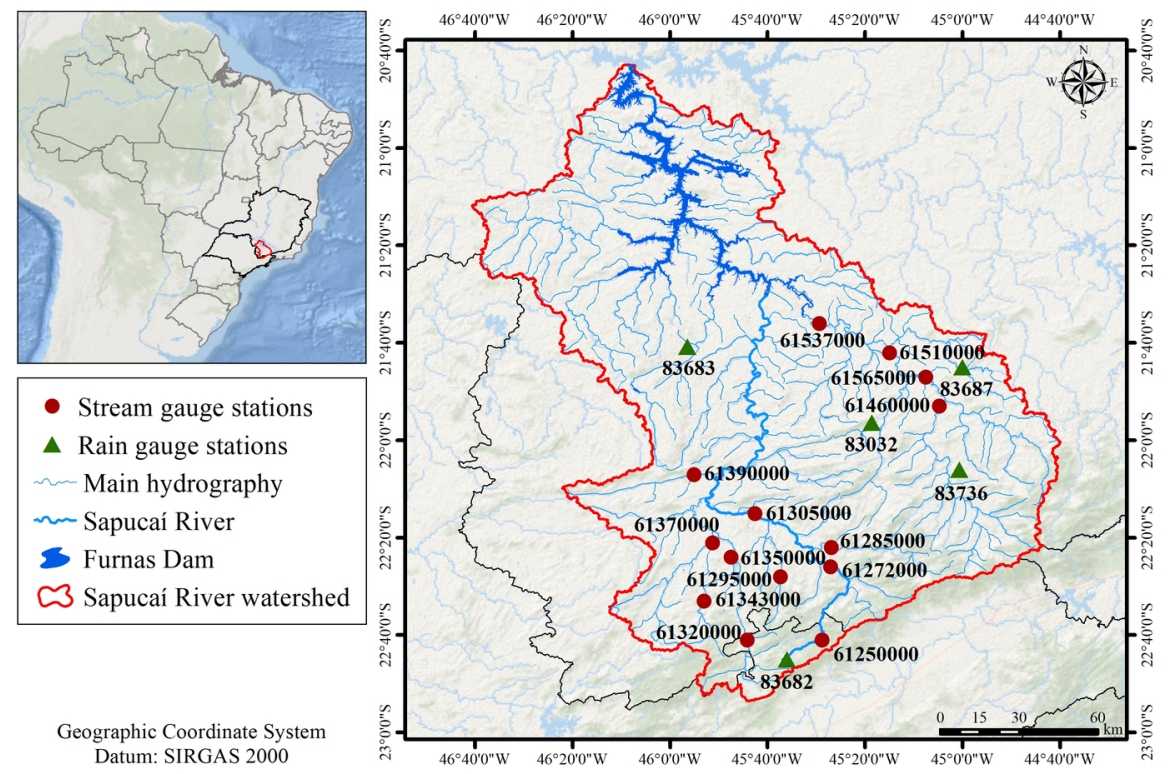

Geographic Coordinate System Datum: SIRGAS 2000

- Stream gauge stations

- Rain gauge stations

Main hydrography

n Sapucaí River

5 Furnas Dam

3 Sapucaí River watershed

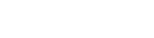
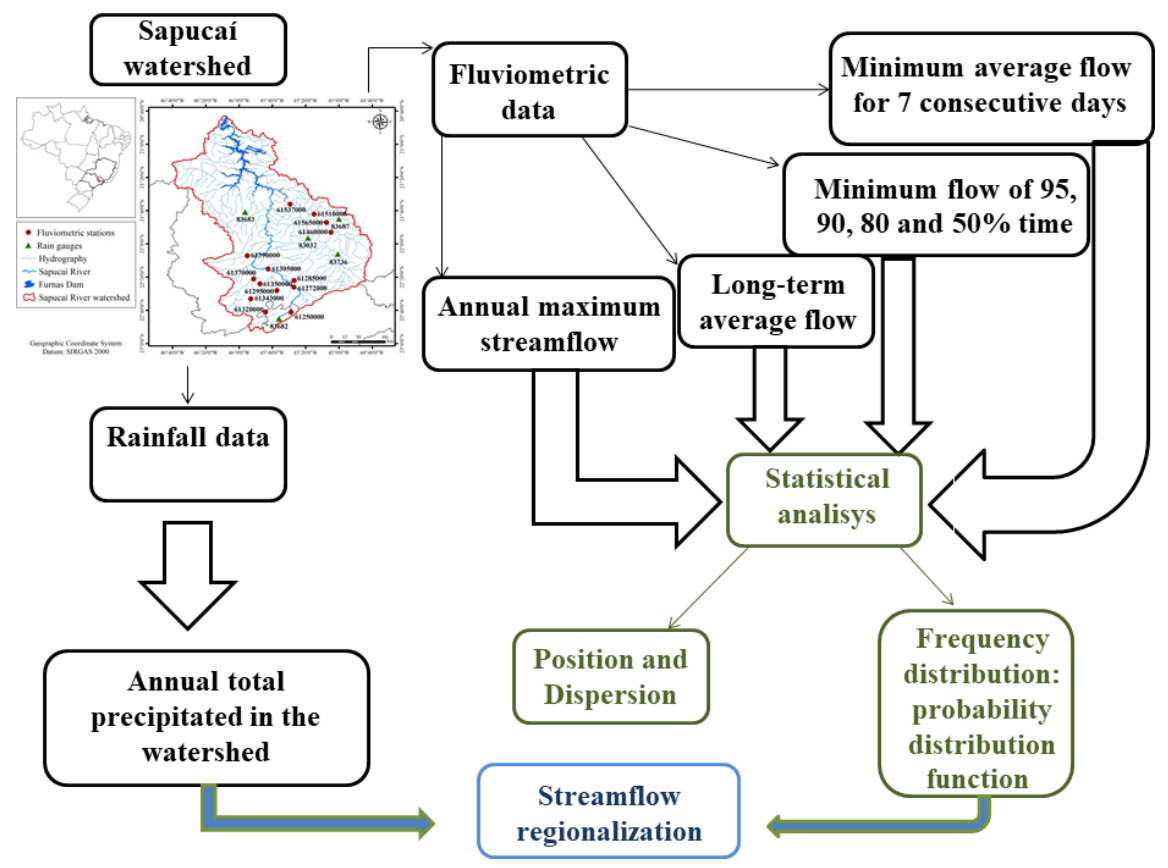

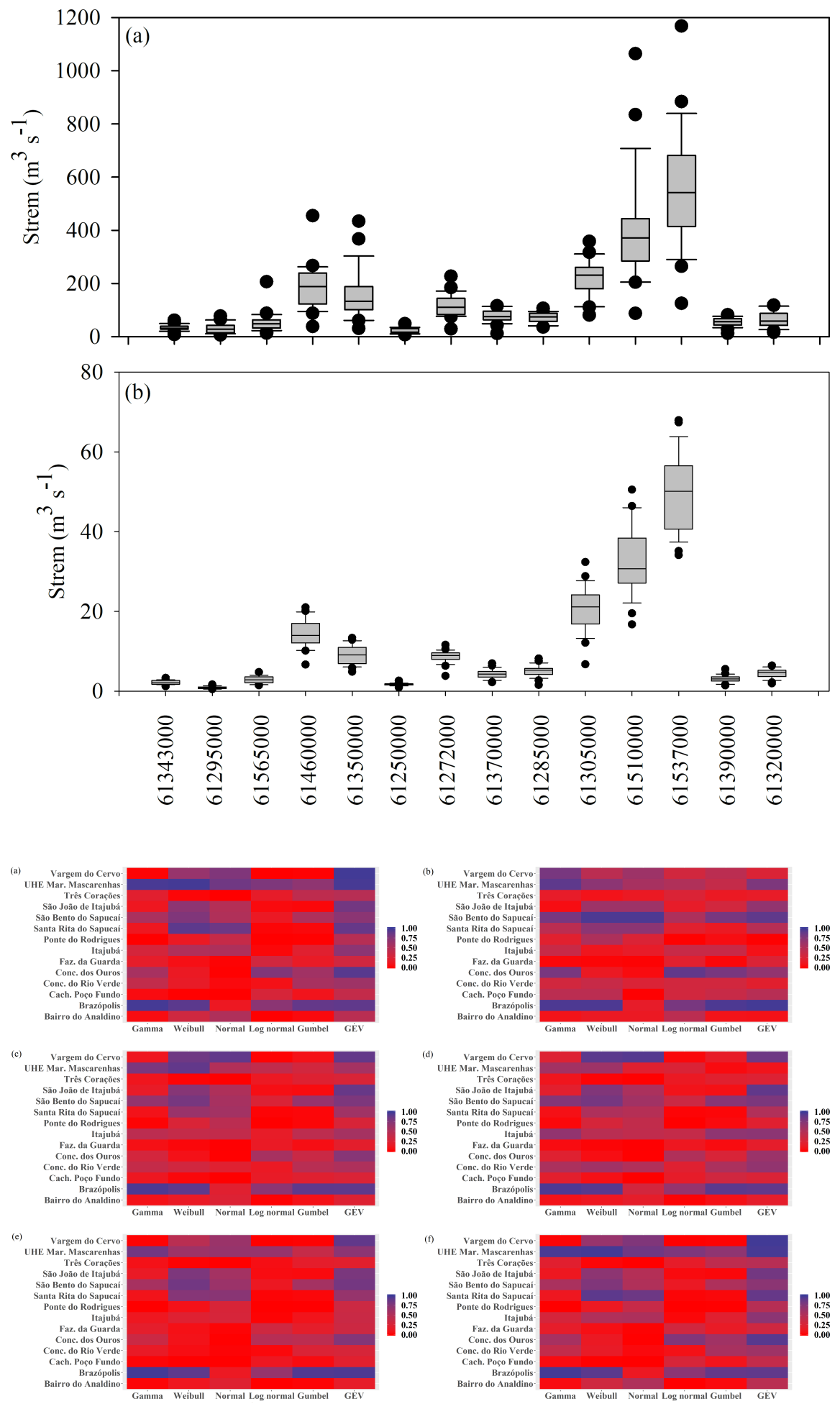

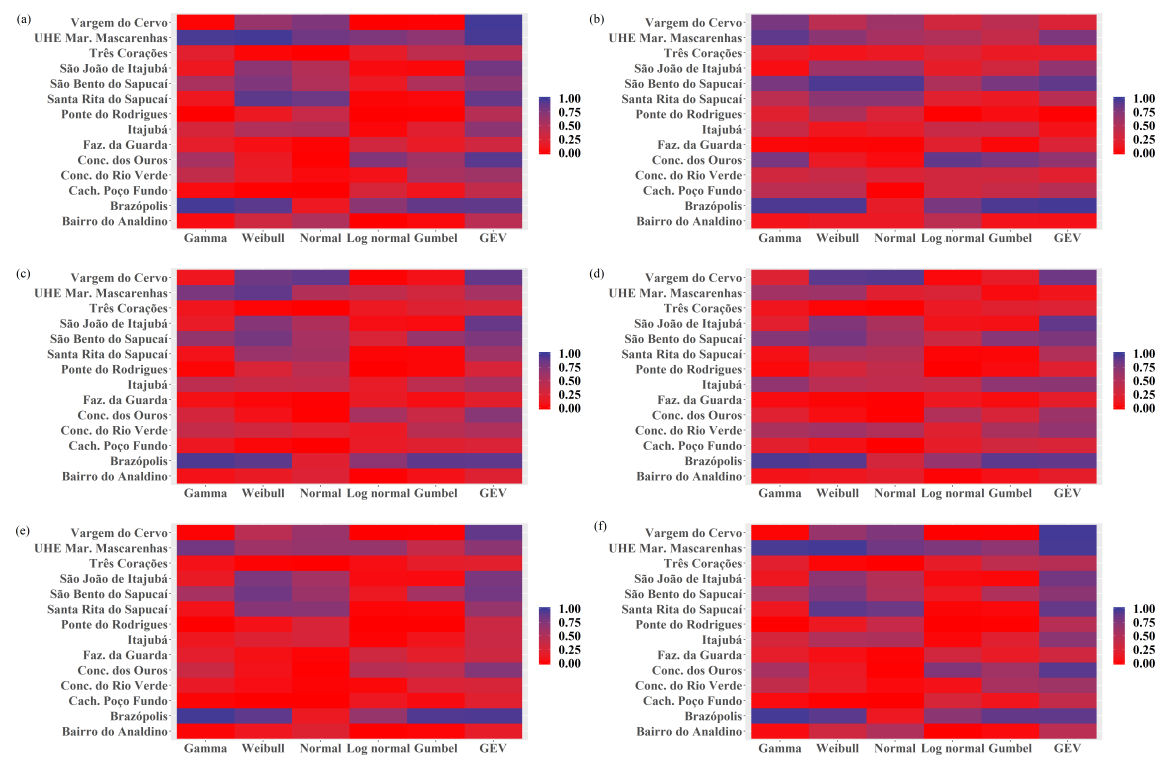

(a)
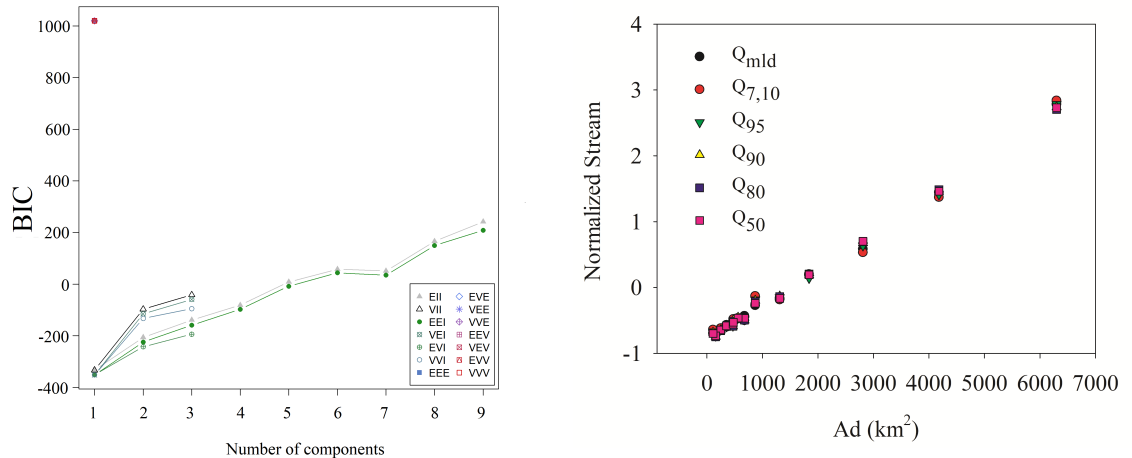